\title{
Variations in Composing Behaviours of Academic ESL Writers in Test and Non-test Situations
}

Ernest Hall

\begin{tabular}{|c|c|}
\hline $\begin{array}{l}\text { While composing process research has } \\
\text { revealed great variation among writers and } \\
\text { among types of writers, research has } \\
\text { largely ignored fluctuation in writing } \\
\text { behaviours of a single writer. This study } \\
\text { contrasted both texts and behaviours of six } \\
\text { ESL writers as they wrote a practice essay } \\
\text { test with their texts and behaviours in an } \\
\text { actual English composition proficiency } \\
\text { examination. } \\
\text { Fluctuations were observed in the com- } \\
\text { plexity of the texts generated, in the alloca- } \\
\text { tion of time to various activities, in the }\end{array}$ & $\begin{array}{l}\text { type of alterations they made while inscrib- } \\
\text { ing. In addition, the six writers displayed } \\
\text { six unique profiles. } \\
\text { The findings suggest that assessment } \\
\text { practices need to distinguish writing prob- } \\
\text { lems from language problems and that } \\
\text { instructional practices need to attend to } \\
\text { composing behaviours, accommodating } \\
\text { students who are apprehensive about writ- } \\
\text { ing or anxious about tests. The findings } \\
\text { reiterate the long-standing suspicion about } \\
\text { the validity of assessing writing skill } \\
\text { through a single text. }\end{array}$ \\
\hline
\end{tabular}

Early studies of writing variation conclusively documented fluctuation in the quality of text generated at different times by a given writer (Kincaid 1953, Anderson 1960). Such fluctuations are common knowledge to experienced writers and composition teachers alike.

The study reported here derived from recent experience in English programmes for foreign students at a large Canadian university where students with high levels of general proficiency in English often fail to meet the university's writing proficiency requirements contrary to predictions by their ESL instructors. The study explored the possibility that the pressure of an examination situation was related to variation in writing behaviours for such writers. The process-tracing techniques employed in this study enabled observation of composing behaviours with the focus on what the writers did in the two situations rather than on what they wrote.

\section{The Research Questions}

Among the questions addressed by this study were the following:

What observable differences were there in the quality of text produced in a non-test situation compared with the quality of text produced during a test for proficiency in written English?

What differences were observed in planning, drafting, and revising 
behaviours, in the ways the writers allocated their time, and in the frequencies, durations, and locations of pauses while they composed in the test and non-test situations? What differences were evident in attention to mechanical and lexical features of text versus matters of a conceptual or discourse nature?

Finally, were relationships evident between observed differences in the behaviour of these writers in the examination and non-test situations and the levels of text anxiety they reported?

\section{Context of the Study}

Concurrent with the shift in recent decades from a research interest in pedagogy and text quality to exploration of composing processes has been a growing interest in understanding process problems which inhibit effective production of text. Among the inhibiting phenomena identified have been inappropriate attention to language form (Shaughnessy 1977, Perl 1979, Zamel 1982), "writing apprehension" (Daly \& Miller 1975), and "writer's block" (Rose 1980, 1984).

In ESL composing, Jones (1985) concluded that writers may rely to different degrees on the "monitor" (Krashen 1976); that is, monitor "overusers" display more frequent and longer pauses during composing and perform fewer revisions than "underusers." Recent evidence supports these conclusions, suggesting that "excessive monitoring for grammatical accuracy can be detrimental, especially if students are trying to apply complex rules which are not yet part of their basic L2 competence" (Adamson 1989, cited by Gungle and Taylor, p. 239). Roen et al (1989) likewise conclude that focus on form most likely raises the level of ESL students' writing apprehension, leading to cognitive overload and preventing ideas from getting on paper.

In studies of "writing apprehension," (the tendency of certain individuals to be generally anxious about writing,) both in English as a first language and in ESL composing, a number of findings have emerged. Apprehensive academic writers were found to favour disciplines with low writing demands (Daly and Shamo 1978). Selfe (in Rose 1985) found an apprehensive writer spent little time in pre-writing activities, hurrying through the inscribing in order to get something onto the page, and Fox (1981) found that a collaborative workshop approach reduced writing apprehension. Composition tasks on language tests were found to be particularly stressful for anxious ESL writers (Madsen and Murray 1984). Fayer (1986) found that writing apprehension increased for writers composing in a second language, and other research found that premature editing was a problem for freshmen ESL writers especially (Betancourt 
and Phinney 1987). Writing apprehension was found to be a real problem among ESL writers (Gungle and Taylor 1989).

Another debilitating phenomenon, "writer's block," was found to involve negative attitudes to writing, lack of strategies for organizing complex material, and tendencies to edit prematurely (Rose 1980, 1984). Harris (1985) identified blocking writers of five different types: the "indecisive writer," the writer overly concerned with "what is right," the "incessant editor," the writer "misguided about a useful strategy," and the "incessant rereader."

Throughout the research in composing processes, several types of behavioural variations have been observed. These variations have typically been among different individual writers (such as those observed by Harris) or between groups of writers (such as the skilled and unskilled writers observed by Perl). Raimes (1985) concluded, that no clear profile of the unskilled ESL writer emerged. Arndt (1987) found differences among her six Chinese writers in the ways they approached the writing task, and Lay (1983) found differences in approaches to pre-writing activities. Jones and Tetroe (1986) noted differences in planning processes, and Johnson (1985) found differences in the use of large-scale plans and in ability to respond to all parts of a rhetorical problem. Brooks (1985) reported variation among writers with regard to audience and in the time used to complete a writing task.

These research findings and observations that certain ESL writers produce English text of inconsistent quality prompt the question: Do such writers behave differently while writing two essays in English-one of which is an actual examination affecting academic status? By closely observing six such writers composing under both test and non-test conditions, the present study extends the understanding of ESL composing processes by examining variations in the behaviours of six writers which may account for the fluctuation in the quality of text they produced.

\section{The Study}

The study was both descriptive and exploratory in design and employed standardized instruments as well as video-taped protocols and post hoc interviews commonly employed in composing process-tracing research (Matsuhashi \& Cooper 1978, Rose 1980, Schumacher 1984, Yau 1989). ${ }^{1}$

\section{The Subjects}

Subjects were selected from a population of 70 graduate and undergraduate students on conditional academic status while taking a required, 
non-credit, cost-recovery ESL writing course preparing them for a 300 word essay examination. Most often, a student taking the required ESL course for the first time fails the exit essay requirement which the students often perceive to be a needless bureaucratic impediment to acquiring full academic status.

From this population, six students volunteered to participate in the study. They had recently failed the ESL essay examination contrary to their instructors' predictions and had been granted permission to challenge the course by writing the exit examination at the end of the subsequent course. As reported in Table 1, the subjects were from a variety of language groups and were diverse in age, previous English studies, and length of time in Canada. They also varied in their scores on the Test of English as a Foreign Language (TOEFL). Frank, Liba, and Shiro ${ }^{2}$ reported greater apprehension about writing than did their ESL peer group. Frank and Kei reported greater anxiety about tests in general than did their peers.

Table 1

Profiles of Subjects ${ }^{\mathrm{a}}$

English Appre-

Time in ESL Test Studies TOEFL hension Anxiety

Subject Age Sex L1 Canada Failures (Years) Score $(z)^{\text {c }} \quad(z)^{\text {b }}$

\begin{tabular}{llllllllll}
\hline Frank & 25 & M & German & 8 months & 2 & 8 & 590 & +0.38 & +0.75 \\
Kei & 20 & M & Japanese & 5.5 years & 6 & 4 & 600 & -0.27 & +0.38 \\
Wang & 18 & M & Cantonese & 7 months & 2 & 13 & 630 & -0.81 & -0.10 \\
Jolanta & 31 & F & Polish & 6.5 years & 3 & 5 & 561 & -0.54 & -0.95 \\
Liba & 37 & F & Czech & 3 years & 3 & 6 & 545 & +2.57 & -1.91 \\
Shiro & 24 & M & Japanese & 7 months & 2 & 12 & 523 & +0.91 & -1.43
\end{tabular}

a. Subjects reporting the greatest changes in anxiety between the two writing situations are listed in initial positions in all tables to facilitate visual comparisons on various measures.

b. Compared with ESL peers on Alpert-haber Achievement Anxiety Test $(\mathrm{N}=51)$. (Because the language of the 19 items on this Likert-type questionnaire was confusing, the items were modified and correspondence of the revised items checked by four ESL specialists who confirmed that the essence of the original items was preserved in the modifications.)

c. Compared with ESL peers on Daly-Miller Writing Apprehension Instrument ( $\mathrm{N}=$ 63). 


\section{Manipulation of Writing Situation Variables}

To ensure that the Situation 2 examination task was no more difficult than the non-test Situation 1 task, the 120-minute period officially allocated to the examination was reduced to 100 minutes for the non-test situation. For the same reason, topics provided for the non-test situation were intentionally more difficult than those provided for the examination. (See Appendix 1.) Subjects reported that the examination topics were easier, and nine ESL composition instructors and 40 advanced ESL writing students ranked the non-test topics as being more difficult than the examination topics. (These efforts to make the test situation easier entailed a research risk that the subjects would produce higher quality examination texts as a result.)

\section{The Writing Tasks}

Before beginning the writing tasks, subjects completed the Spielberger State Anxiety Inventory (1968) questionnaire to measure the degree to which they were anxious about the particular situation. They wrote the non-test and examination papers several weeks apart, in isolation with only the researcher present. The video camera focussed only on the paper being written. During video taping, tapes were regularly switched in order to record three 10-minute segments from the beginning, middle, and end of the writing tasks for use in the stimulated-recall interviews immediately following the writing tasks. The post hoc interviews were audio taped and ranged from 45 to 60 minutes long.

\section{Text Quality}

The texts were compared according to differences in quality as assessed by the ESL course procedures which involved a minimum of two markers who deducted points for textual weaknesses classified as content, organization, sentence structure, grammar, diction, and mechanics. (See Appendix 2.) The texts were also compared for differences in syntactic complexity according to T-unit length (Hunt 1970).

\section{Process Tracing}

Process-tracing procedures enabled comparisons of time spent in prewriting, drafting, and post-draft activities, durations, frequencies, and locations of pauses during forward inscribing, and frequencies of various types of changes made in extant text during inscribing. For this purpose, samples of the inscribing periods involving approximately 100 words of each text generated (approximately one-third of the minimum length 
required) were selected. Care was taken to ensure that the periods sampled were indeed instances of inscribing and not of revising or copying previously generated text.

Pauses were classified according to length: 10-29 seconds, $30-59 \mathrm{sec}-$ onds, and those exceeding 60 seconds. Pauses were also classified by location either within clauses or phrases or outside clauses or phrases. Alterations (changes in extant text) during the inscribing periods sampled were classified as High Level (Conceptual or Discourse) or Low Level (Mechanical or Lexical). Instances when the writer reformed letters were classified as Cosmetic.

\section{Coding Agreement}

In coding the pauses and alterations, agreement checks were conducted between classification by the researcher and a TESL graduate student. Inter-rater agreement was .93 for pause locations and .91 for alteration level.

\section{Data Presentation and Analysis}

Comparisons mainly involved Spearman rank correlations on the various measures used and ratio comparisons between data collected in the two situations. The small number of subjects often resulted in comparisons that were not statistically significant at the .95 or .99 levels of confidence ${ }^{3}$, but are nonetheless of interest in an exploratory study such as this.

\section{Results: Anxiety}

As Table 2 reports, four subjects, Frank, Wang, Kei, and Liba, indicated increases in state anxiety from Situation 1 (the non-test) to Situation 2 (the examination) ranging from $\mathrm{z}$-score increases of +.12 to +1.70 . Scores for Jolanta and Shiro indicated decreases in anxiety levels of .71 and .19 respectively. Subjects indicating the greatest increases, Frank, Kei, and Wang, who also scored high on either the Writing Apprehension and Achievement Anxiety instruments, were regarded as High Anxious and the others as Low Anxious for further comparisons. ${ }^{4}$

\section{Text Qucility}

As Table 3 indicates, text quality for the two situations varied greatly according to the course assessment. Variation in quality ranged from a decrease of 18 per cent in the case of Wang to an increase of 40 per cent in the case of Shiro. The "composition fluctuation" documented by Kincaid and Anderson was clearly evident in these situations. 
Table 2

Scores on Spielberger State Anxiety Inventory

\begin{tabular}{|c|c|c|c|c|c|c|c|}
\hline \multirow{2}{*}{ Subject } & & \multicolumn{2}{|c|}{$\begin{array}{l}\text { Situation } 1 \\
\text { Non-Test }\end{array}$} & \multicolumn{2}{|c|}{$\begin{array}{c}\text { Situation } 2 \\
\text { Test }\end{array}$} & \multirow{2}{*}{$\begin{array}{l}\text { Difference } \\
\text { in } z\end{array}$} & \multirow[b]{2}{*}{ Rank } \\
\hline & & Raw & $\mathrm{z}$ & Raw & $\mathbf{z}$ & & \\
\hline \multicolumn{2}{|l|}{ Frank } & 35 & -0.15 & 52 & +1.55 & +1.70 & 1 \\
\hline \multicolumn{2}{|l|}{ Kei } & 45 & +0.85 & 48 & +1.15 & +0.30 & 3 \\
\hline \multicolumn{2}{|l|}{ Wang } & 40 & +0.35 & 51 & +1.45 & +1.10 & 2 \\
\hline \multicolumn{2}{|l|}{ Jolanta* } & 53 & +1.19 & 43 & +0.35 & -0.71 & 6 \\
\hline \multicolumn{2}{|l|}{ Liba* } & 37 & +0.15 & 42 & +0.27 & +0.12 & 4 \\
\hline \multicolumn{2}{|l|}{ Shiro } & 24 & -1.24 & 26 & -0.15 & -0.19 & 5 \\
\hline \multirow{2}{*}{\multicolumn{2}{|c|}{$\begin{array}{l}\text { Means: } \\
\text { S.D. }\end{array}$}} & \multicolumn{2}{|l|}{39.00} & \multicolumn{2}{|l|}{43.67} & & \\
\hline & & 9.78 & & 9.56 & & & \\
\hline \multirow[t]{3}{*}{ Norms: } & Mean & \multicolumn{4}{|l|}{36.47} & & \\
\hline & S.D. & \multicolumn{4}{|c|}{10.02} & & \\
\hline & $\mathrm{N}$ & \multirow{2}{*}{\multicolumn{4}{|c|}{$\begin{array}{l}324 \text { College Students } \\
38.76\end{array}$}} & & \\
\hline \multirow[t]{3}{*}{ *Females: } & Mean & & & & & & \\
\hline & S.D. & \multirow{2}{*}{\multicolumn{4}{|c|}{$\begin{array}{l}11.95 \\
531 \text { College Students }\end{array}$}} & & \\
\hline & $\mathrm{N}$ & & & & & & \\
\hline
\end{tabular}

Table 3

Scores and Variations in Text Quality

Text $1 \quad$ Text 2

(Non-test) (Test) Variation

$\begin{array}{lllll}\text { Subject } & \text { Raw } & \text { Raw } & \text { Raw }\end{array}$

\begin{tabular}{llllll}
\hline Frank & 58 & 64 & +6 & +.10 & 2 \\
Kei & 45 & 40 & -5 & -.07 & 4 \\
Wang & 79 & 65 & -14 & -.18 & 6 \\
Jolanta & 55 & 51 & -4 & -.07 & 3 \\
Liba & 53 & 41 & -8 & -.15 & 5 \\
Shiro & 48 & 67 & +19 & +.40 & 1 \\
\hline
\end{tabular}




\section{Syntactic Complexity}

For all subjects, mean T-unit length for texts produced in the examination situation was significantly greater (rho $=.94$ where the critical value for $\mathrm{p}<.05$ is .83) than in the non-test compositions, on average, an increase of 14 per cent (from 15.97 to 18.14 words). In addition, as Table 4 indicates, the increase in the complexity of text for one writer was proportionate to increases by the other five writers; that is, rankings for syntactic complexity were similar in the two situations except for those writers in first and second rankings (Kei and Wang).

Within subjects, however, increases in syntactic complexity from the first to the second situation varied greatly. Mean T-unit length increased from three per cent (for Frank and Wang) to 29 per cent for Jolanta.

Table 4

Mean T-Unit Length

\begin{tabular}{|c|c|c|c|c|c|c|c|c|}
\hline \multirow[b]{2}{*}{ Subject } & \multicolumn{3}{|c|}{ Text 1} & \multicolumn{3}{|c|}{ Text 2} & \multirow{2}{*}{$\begin{array}{c}\text { Variation } \\
(\%)\end{array}$} & \multirow[b]{2}{*}{ Rank } \\
\hline & Mean & $\mathrm{n}$ & $\mathbf{R}$ & Mean & $\mathbf{n}$ & $\mathbf{R}$ & & \\
\hline Frank & 11.84 & 37 & 6 & 12.21 & 33 & 6 & +.03 & 5.5 \\
\hline Kei & 18.07 & 15 & 2 & 22.95 & 22 & 1 & +.27 & 2 \\
\hline Wang & 22.28 & 18 & 1 & 22.94 & 16 & 2 & +.03 & 5.5 \\
\hline Jolanta & 16.50 & 26 & 3 & 21.30 & 23 & 3 & +.29 & 1 \\
\hline Liba & 13.81 & 26 & 4 & 15.19 & 37 & 4 & +.10 & 3 \\
\hline Shiro & 13.32 & 31 & 5 & 14.23 & 26 & 5 & +.07 & 4 \\
\hline Means: & 15.97 & & & 18.14 & & & & \\
\hline
\end{tabular}

A Spearman correlation of rankings for T-unit increases and increases in anxiety suggested (although not statistically significant) a moderately high inverse relation (rho $=-.73$ ); that is, the greater increase in anxiety experienced by the writer, the lower the increase in complexity of the writing produced.

On the other hand, the third High Anxious subject, Kei produced an examination text 27 per cent more syntactically complex than his Situation 1 text. Perhaps this was because, as he revealed in the Situation 2 interview, for the examination composition he chose a topic on which he had previously written several times and thus was able to devote a greater amount of attention to syntactic aspects than to generation and organization of content. 


\section{Syntactic Complexity and Text Quality}

A correlation of rankings for increase in complexity and text quality indicated a low to moderate inverse relationship (rho $=-.36$ ). Little relation was evident between an increase in syntactic complexity and improvement in text quality.

\section{Time Allocation}

The proportion of the total time spent by these writers in pre-writing, inscribing, and post-drafting activities is presented in Table 5. A Spearman rank correlation of proportions of time spent in pre-writing in the two situations indicated a low to moderate relationship (rho $=.37$ ). This suggests that the writers allocated their time differently to the three activities in the two situations. However, when the proportions were removed for Liba (whose Situation 2 pre-writing time was minimal because, as she said, she knew immediately what she would write), the correlation was statistically significant (rho $=.90$, where the critical value for $\mathbf{p}<.05$ with $\mathbf{n}=5$ is .90 ). With the exception of Liba, these writers allocated time to pre-writing activities in similar proportions in the two situations.

Comparisons of rankings of the six writers for inscribing and post-draft activities in the two situations were highly significant (rho $=.943$, where the critical value for $p<.01$ is .943). Clearly, these writers allocated their time to the three activities in similar ways in the two situations.

Table 5

Proportion of Time Spent in Pre-Writing, Inscribing, and Post-Drafting Activity (Percentage of Total Time)

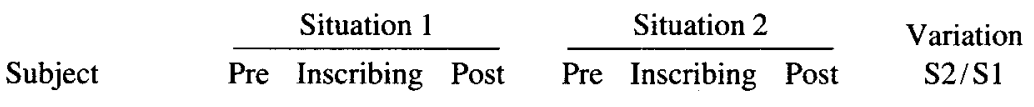

\begin{tabular}{lrrrrrrr} 
Frank & 7 & 46 & 46 & 5 & 40 & 55 & -.13 \\
Kei & 48 & 50 & 2 & 43 & 54 & 3 & +.08 \\
Wang & 13 & 39 & 49 & 11 & 31 & 58 & -.21 \\
Jolanta & 17 & 81 & 2 & 18 & 80 & 2 & -.01 \\
Liba & 19 & 79 & 2 & 3 & 82 & 15 & +.04 \\
Shiro & 11 & 66 & 23 & 16 & 62 & 23 & -.06 \\
\hline
\end{tabular}




\section{Anxiety and Inscribing Time}

As indicated in Table 5, the High Anxious subjects devoted a smaller proportion of their time to inscribing in both situations than the proportion allocated by the Low Anxious subjects. A significant correlation of .84 (p $<.05=.83$ ) suggests a relationship between these two measures, but a more plausible explanation might be their relative proficiency in English as indicated by their TOEFL scores. Greater proficiency may have enabled them to generate text at a faster rate, providing them with more time for other activities.

\section{Pause Frequencies}

Percentages calculated for frequencies of pauses of the three durations showed variation from Situation 1 to Situation 2. As reported in Table 6, the average number of pauses 10-29 seconds long decreased by seven per cent (from 9.33 to 8.67) while the mean numbers of mid-length pauses and pauses greater than 59 seconds long increased by 15 and 32 per cent respectively. Only for Liba, writing on a topic with which she was more at ease than with the one she chose in the non-test Situation 1, did the mid-length pauses and those greater than 60 seconds long decrease in frequency in the examination. With the exception, perhaps, of Liba, these increases in pauses of longer duration may indicate that these writers, a group generally accustomed to failure when writing an essay examination, were negatively affected by the test situation; that is, their ability to commit language which they had generated to paper may have been impeded, resulting in pauses of greater duration.

Table 6

Frequencies of Pauses

\begin{tabular}{lcccccc} 
& \multicolumn{3}{c}{ Situation 1} & \multicolumn{3}{c}{ Situation 2 } \\
\cline { 3 - 6 } Subject & $10-29 *$ & $30-59$ & $60+$ & $10-29$ & $30-59$ & $60+$ \\
\hline Frank & 5 & 2 & 1 & 9 & 3 & 2 \\
Kei & 8 & 4 & 1 & 6 & 0 & 5 \\
Wang & 9 & 2 & 1 & 7 & 6 & 1 \\
Jolanta & 13 & 3 & 7 & 7 & 7 & 11 \\
Liba & 10 & 5 & 6 & 13 & 4 & 2 \\
Shiro & 11 & 4 & 3 & 10 & 3 & 4 \\
Means: & 9.33 & 3.33 & 3.17 & 8.67 & 3.83 & 4.17 \\
\hline
\end{tabular}

* Seconds 
Two observations of interest are that for Kei, writing on a familiar topic in Situation 2, the sample revealed a greater frequency of long pauses, and for Liba, writing on a Situation 2 topic which she felt was easier, the greatest variation was in shorter pauses. This suggests these two writers displayed different ways of generating text when writing on relatively easy topics; perhaps Kei, writing on a topic of familiar content, deliberated at length over language concerns, while Liba, who knew from the outset what she would write, paused more often to deal with problems which were quickly solved. On the other hand, perhaps the increase in pauses of more than 60 seconds for Kei, a High Anxious writer, was a function of an increase in anxiety toward the examination. Moreover, Kei's lengthy pauses may have resulted from his attempting to recall language structures he had used when writing on the topic previously.

\section{Pausing Durations and Inscribing}

For individuals, variations in mean pause length, in the proportion of inscribing time spent in pauses, and in speed of inscribing were mixed (as reported in Table 7). For Frank and Liba, mean pause length for the inscribing sample decreased in the examination situation. For the others, mean pause length increased. For four writers, the proportion of the total time in the inscribing sample spent in pauses of greater than 10 seconds long increased, while for Liba, it decreased and for Jolanta remained the same. A significant correlation (rho $=.89$ where the critical value for $p$ $<.05$ is .83) was found between anxiety level increase and the variation in proportion of time pausing during the inscribing samples. All subjects but Jolanta inscribed at a considerably faster rate during the Situation 2 examination inscribing sample than they did in the non-test situation.

Table 7

Inscribing Variations Between Situations (Percentages)

\begin{tabular}{lcccccc} 
& $\begin{array}{c}\text { Mean } \\
\text { Pause } \\
\text { Length } \\
\text { Variation }\end{array}$ & $\begin{array}{c}\text { Time } \\
\text { Pausing } \\
\text { Variation }\end{array}$ & $\begin{array}{c}\text { Inscribing } \\
\text { Rate } \\
\text { Variation }\end{array}$ & $\begin{array}{c}\text { Type 2 } \\
\text { Pause } \\
\text { Ratio }\end{array}$ & $\begin{array}{c}\text { S-2 } \\
\text { Type 2 } \\
\text { Pause } \\
\text { Ratio }\end{array}$ & $\begin{array}{c}\text { Pause } \\
\text { Ratio } \\
\text { Variation }\end{array}$ \\
\hline Frank & -7 & +38 & +63 & .13 & .43 & +.30 \\
Kei & +58 & +38 & +19 & .62 & .14 & -.48 \\
Wang & +31 & +38 & +37 & .25 & .14 & -.11 \\
Jolanta & +54 & 0 & -35 & .30 & .32 & +.02 \\
Liba & -47 & -12 & +40 & .33 & .26 & -.07 \\
Shiro & +51 & +23 & +29 & .28 & .29 & +.01 \\
\hline
\end{tabular}


A comparison of anxiety increase and variations in both mean pause length and inscribing rate gave moderate correlations of -.66 and .49 respectively. While these are not statistically significant, an inverse relationship is suggested between increase in anxiety and variation in mean pause length. However, because of the extreme scores for Frank, for whom anxiety increased the most but whose pause length varied least, this apparent correlation must be considered cautiously. The moderate relationship suggested between anxiety increase and inscribing rate (rho $=.49$ ) may be regarded with less caution; that is, because no extremes are apparent in the rankings, the suggestion that inscribing rate for these writers increased as anxiety increased may have been tenable had the number of subjects been larger.

\section{Pause Locations}

Data reported in Table 7 indicate that pause locations in relation to syntactic units varied between the two situations. For three writers, Frank, Jolanta, and Shiro, the ratio of Type 2 pauses (those within clauses or phrases) to Type 1 pauses (those between syntactic units) increased, while for the others, the proportion decreased.

A Spearman correlation of ranks on increase in anxiety and these variations in ratio suggests a fairly strong relationship (rho $=.77$, where the critical value for $\mathrm{p}<.05$ is .83 ). ${ }^{5}$ While this is not statistically significant, it must be noted that the subjects exhibiting the greatest increase in anxiety between the two situations also showed the greatest variation $(30,48$, and 11 per cent respectively) in the locations of their pauses in the inscribing samples examined. Perhaps increases in anxiety regarding the examination resulted in hesitations in inscribing at different levels of text generation for these writers to a greater extent than for the Low Anxious group. For instance, the greater anxiety reported by Kei and Wang may have led them to ponder more at the beginnings of syntactic units during the examination than they had in the non-test situation, while increased anxiety may have had the reverse effect on Frank, causing him to rush from one syntactic unit into the next.

\section{Alterations During Forward Drafting (Inscribing)}

The occurrences of Lexical and Mechanical alterations performed during the inscribing samples, classified as Low Level alterations, and of Discourse and Conceptual changes, classified as High Level, are presented in Table 8. For the entire group, the total number of alterations (93 for Situation 1 and 92 for Situation 2 with means of 15.5 and 15.3 respectively) varied little from the non-test to the examination situation. Nor did the total numbers of Low Level and High Level alterations vary greatly. 
The number of alterations performed by each writer was proportionate to the number performed by the other five writers in both situations. The High Anxious writers performed 68 per cent of the 93 alterations in the Situation 1 inscribing sample and 65 per cent of the alterations in the Situation 2 samples.

\section{Table 8}

Alterations During Inscribing

Situation 1

Alteration Types \%

Subject
Situation 2

Alteration Types \&

C Low High Total High

\begin{tabular}{lrrrrrrrrrr}
\hline Frank & 7 & 17 & 9 & 26 & 35 & 4 & 13 & 12 & 25 & 48 \\
Kei & 4 & 11 & 7 & 18 & 39 & 5 & 11 & 2 & 13 & 15 \\
Wang & 7 & 13 & 6 & 19 & 32 & 16 & 11 & 11 & 22 & 50 \\
Jolanta & 3 & 4 & 1 & 5 & 20 & 6 & 4 & 3 & 7 & 43 \\
Liba & 0 & 5 & 4 & 9 & 44 & 0 & 8 & 4 & 12 & 33 \\
Shiro & 0 & 7 & 9 & 16 & 56 & 3 & 7 & 6 & 13 & 46 \\
Totals: & 21 & 57 & 36 & 93 & & 34 & 54 & 38 & 92 & \\
Means: & & 9.5 & 6 & 15.5 & & & 9 & 6.3 & 15.3 & \\
S.D. & & 5.0 & 3.1 & 7.5 & & & 3.3 & 4.2 & 6.7 & \\
& & & & & & & & &
\end{tabular}

C: $\quad$ Cosmetic Alterations

High: Discourse and Conceptual Alterations

Low: Lexical and Mechanical Alterations

In percentage terms, Jolanta, the least anxious writer, performed 23 per cent more high-level alterations in the examination situation than she did in Situation 1, but her alterations were so few in number (five and seven respectively) that this increase must be interpreted cautiously. If, for this reason, this ratio variation is removed for Jolanta, these data for High Anxious writers Frank and Wang represent the greatest increase in this variation, while the inscribing samples for the third High Anxious writer, Kei, reveal the greatest decrease ( 24 per cent). A relationship is suggested between anxiety and variation on this measure, albeit variation in different directions. Perhaps for Frank and Wang, examination pressure resulted in their attending more to high-level concerns than they had in the non-test situation. Perhaps the apparent decrease in this concern for Kei can be explained by his familiarity with the Situation 2 topic on which he had written before. In this case, Kei's grasp of the content and organization 
may have enabled him to devote a greater amount of his attention to matters of a lexical and mechanical nature (also resulting in the great increase in syntactic complexity noted earlier).

As reported in Table 8, subjects with tendencies to perform cosmetic alterations (reformation of characters) tended to do more of this in the examination situation. Perhaps this behaviour was related to the pressure of the examination. Of particular interest in this regard is Wang, one of the High Anxious subjects, whose cosmetic alterations more than doubled in Situation 2 even though he was inscribing a rough draft. ${ }^{6}$ Noteworthy also is that, of the total 55 cosmetic alterations observed in the 12 inscribing samples, 43 were by writers in the High Anxious group. For the entire group, cosmetic alterations increased by 62 per cent, from 21 to 34, in the examination situation. These data strongly suggest that cosmetic alteration behaviours were related to anxiety.

\section{Summary of Findings}

According to assessment procedures used, quality of texts produced in the non-test and examination situations varied greatly (ranging from seven to 40 per cent). All of the subjects produced examination texts syntactically more complex than their non-test papers. In addition, the increase in complexity of their texts was roughly proportionate to increases by the other five writers.

The subjects allocated their time to pre-writing, inscribing, and postdrafting activities in similar ways in the two situations. However, when they were not engaged in pauses greater than 10 seconds long, five of the subjects wrote at a considerably faster rate in the examination than they did in the non test situation (even though the examination time was 20 minutes longer). For five subjects, longer pauses were more evident in the examination situation than in the non-test situation. For the entire group, the number of alterations to extant text and the ratio of Low to High Level alterations varied little between the situations.

The three High Anxious writers were also the most generally proficient in English (as measured by the TOEFL). These writers altered extant text frequently in the inscribing periods sampled from both the test and the non-test situations. Textual alterations indicated these writers attended to lexical and mechanical matters to a greater extent than did the Low Anxious writers. Two of these writers spent less time inscribing and more time in post-draft activity in both situations than did the other subjects in both situations.

According to assessment procedures used, two High Anxious subjects produced examination essays of poorer quality than their non-test papers. 
While syntactic complexity increased for all of the writers in the examination situation, it increased to a lesser degree for those who reported increases in anxiety than for the others. Increases in syntactic complexity for two writers were accompanied by decreases in text quality.

Increase in anxiety level between the situations was accompanied by an increase in the proportion of time spent in pauses greater than 10 seconds long in the inscribing periods sampled. Ratios of pauses within syntactic units to those between syntactic units also varied more for the writers for whom anxiety increased. In addition, the ratio of High Level alteratins of extent text to Low Level alterations varied most for these writers.

In the inscribing periods sampled, writers who tended to perform cosmetic alterations tended to do more of this in the examination situation. The writers with these tendencies were those in the High Anxious group.

Finally, the video records and post hoc interviews of this study revealed six writers who generated text of variable quality for what appeared to be very different reasons. Shiro, for instance, emerged as a confident, capable writer lacking the vocabulary and mastery of grammatical forms required to produce the five-paragraph English essay. Liba on the other hand, demonstrated severe doubts about her ability to convey her ideas in the written form of English.

\section{Discussion and Implications ${ }^{7}$}

Did anxiety play a role in the inability of the writers observed in this study to produce texts of consistent quality? All six of these writers, accustomed as they were to failing examinations of the type under study, exhibited certain behaviours differently in the two situations. To what extent the additional stress was the cause remains a question.

It appers that the examination situation prompted them to generate text of greater syntactic complexity than they did under less stressful conditions. Perhaps the knowledge that they were being tested prompted them to write longer, more complex sentences, an indication that they may have equated complexity of language with writing quality. On the other hand, because all six writers found the examination topic (by intention) easier, perhaps the relative ease of topic permitted them to develop more complex sentences.

That pause lengths and inscribing rates generally increased for all of them in the examination situation suggests that these six writers were prompted both to ponder more and also to race with greater speed against the clock when they were not engaged in pausing activities (despite the longer period for the examination.)

Regardless of the discrepancies among text quality assessments, two of 
the more proficient subjects spent much less of their time inscribing and more of their time engaged in post-drafting activity in both situations. This suggests that greater general proficiency enabled them to generate text at a faster rate than that of the less proficient writers. The same two writers also made many more alterations while inscribing than did the others. General proficiency in English may have enabled these writers to make decisions more quickly than the less proficient writers.

Because the subjects who reported to be generally anxious (AAT score, Table 1) and who reported the greatest increases in state anxiety between the two situations were also those who had the highest TOEFL scores for English proficiency, relations between this proficiency measure and other measures are tenuous. However, the possibility that the more proficient subjects were more anxious because their expectations of passing the examination were especially high and that they perceived themselves to be at greater risk must be considered.

\section{Implications for Assessing Composing Competence}

The variations in quality of the texts generated by the writers in this study support the long-standing conclusions regarding the questionable validity of basing assessment of composing ability on the quality, assessed by any measures, of only one text. That recognized tests (such as the TOEFL, with its component Test of Written English), and educational institutions (such as the university attended by the subjects of this study) continue to base assessment of writing competence on a single sample of a student's writing is strongly called into question.

Likewise, that text quality is generally held to be the prime measure of a writer's composing ability is called into question. Surely the processes these writers employed to generate text need to be considered as valid measures of their composing skill; the texts which resulted stand merely as artifacts of those processes in the two situations observed. Development of assessment procedures which would facilitate evaluation of a student writer's composing behaviours is needed.

In ESL composing, assessment procedures need to address the distinction between writing expertise and English proficiency. The competent writer whose text quality is affected by low proficiency in the second language needs to be identified so that pedagogy can address the writer's real needs.

Finally, writing process assessment procedures need to identify the idiosyncratic characteristics of certain writers who may be apprehensive about writing or anxious in certain situations so that pedagogy can address the problems of these individuals as behaviours which can be altered with instruction rather than merely deficiencies in the ability to write. 


\section{Implications for Teaching}

The findings of this study seriously call into question the practice of focussing instruction on the English essay genre rather than on writing skill. In the interviews conducted in this study, these writers, working to produce the five-paragraph essay, complete with introduction, three-paragraph body, and conclusion, reported high concern for the essay form and for accuracy of language. Little did they reflect on the processes by which they generated, selected, classified, and organized their ideas. Such student writers need to become cognizant of their composing processes and apply them efficiently according to the demands of the particular writing situation. Concerns about textual content and form as well as what is expected need to be reduced. Until such student writers learn to focus and reflect more on how they write rather than on what they write or what they should write, the efforts of writing teachers to affect the composing ability of their students may result in little more than frustration for both students and teachers.

Writing teachers need to adopt means to reduce the effects of anxiety on the ability of some student writers to perform well in stressful writing situations. By enabling student writers to gain insight into their own writing behaviours, perhaps teachers can help them develop strategies for overcoming the effects of stressful situations and their apprehension about writing as they get on with the serious business of learning productively.

In the teaching of ESL writing, students such as Shiro, who demonstrate a high level of composing expertise but low second-language proficiency, need to be identified and treated differently from those such as Liba, for whom the craft of writing has yet to be developed.

\section{Implications for Research Methods}

The six writers in this study, accustomed as they were to failure, had little to lose by participating in the study. An attempt to examine the composing behaviours of a more expert writer, using the techniques employed in this study, would likely be frustrated by the writer's refusal to participate in an examination situation. Process-tracing techniques more sophisticated than the video observation procedures employed here may eliminate the threat of intrusion by the researcher, and thereby enable the investigation of the processes of anyone writing under high-stress test conditions.

\section{Final Notes}

A number of variables not controlled in this study could inform future studies in this area. Although considerable care was taken to ensure that 
the test topics were easier than the non-test topics, the test topic choices included one on which one writer (Kei) had written several times before. Nor did the study ensure uniformity of general English proficiency among the subjects. Nor did the study explore the writing experience among the subjects or their performance and the writing in concurrent academic course work. That the subjects regarded as High Anxious were also those most proficient (as measured by the TOEFL) posed a problem.

Whatever variables were at work in the processes examined in this study, and whatever the degree of caution one must adopt in drawing inferences from this observation of such a small number of subjects, that these research subjects were writing in a situation sponsored neither by school nor by research leaves no question that they were demonstrating, in at least the examination situation, their real writing processes; the academic futures of these students were at stake in the test situation in which they were expected to demonstrate their highest quality English writing.

Braddock, Lloyd-Jones, and Schoer, in 1963, called for composition assessment methods which stimulate writers to perform as best they can. "Surely," they wrote, "there must be some stimulating factor in a topic and, if possible, in the writing situation, too, if the writing they trigger is to have any significance for research" (Page 6).

Whether or not the topic choices available to the six writers in this study were stimulating, the written English proficiency examination observed in Situation 2 , in which so much was at stake, provided a motivation to perform which cannot be denied.

\section{Epilogue}

Following this study, all of the subjects were granted an appeal examination. Two, Kei and Frank, declined the opportunity to write the examination yet again and left the university. The other four wrote the appeal examination. Wang passed, and pursued his studies with full status, unimpeded by the English proficiency requirement. The other three failed.

Liba's appeal examination score was 52 . Her scores on the two papers produced in this study were 53 and 41 . Shiro's appeal examination text received a score of 35 compared with scores of 48 and 67 on the papers he produced in the course of this study. Jolanta produced an appeal examination which scored 34 compared with scores in this study of 55 and 51 .

The findings of this study strongly suggest that the application of procedures which assess the writing skills of such student writers, rather than the quality of the texts they produce, would enable instruction to address deficiencies in writing expertise which otherwise may lead to continued failure. 


\section{APPENDIX 1}

Non-Test Situation 1 Topics:

1. The censorship of books and films is necessary to protect society. Give reasons why you agree or disagree.

2. Discuss the psychological and economic effects of the liberation of women on family life.

3. The lives of your parents were easier than life is for people in your generation. Give reasons why you agree or disagree.

4. Discuss the causes and effects of a serious social problem in your native country.

Examination Situation 2 Topics:

1. Discuss the effects of a significant technological change.

2. Compare the way you used to spend your leisure time in the past with the way you spend your leisure time now.

3. Compare the ideas you had about Canadians before you came to Canada with your present impressions. 


\section{APPENDIX 2}

ESL Course Examination Evaluation Criteria

\section{A WRITING ASSESSMENT-FOR MARKERS ONLY}

March, 1988

STUDENT'S NAME

In evaluating your paper, markers noted a numbers of weaknesses in your work. [Check marks below indicate the types of errors you have made.]

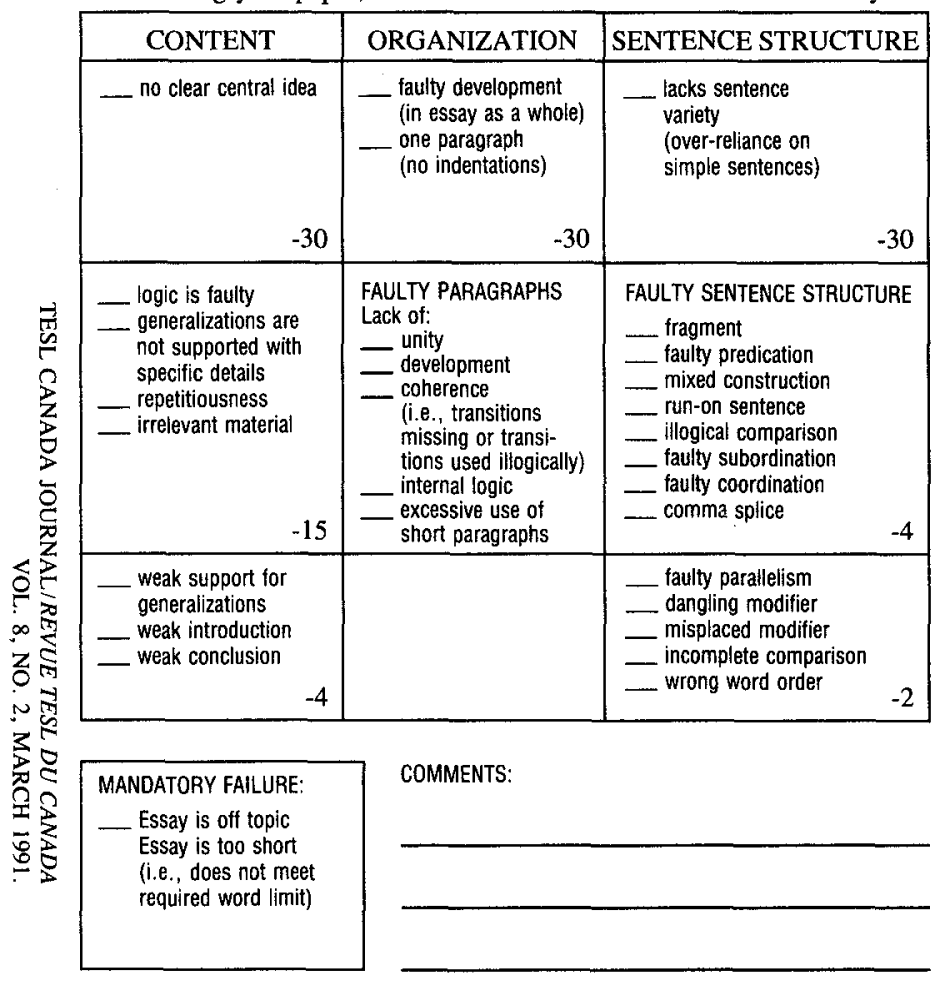

\begin{tabular}{|c|c|c|}
\hline GRAMMAR & DICTION & MECHANICS \\
\hline $\begin{array}{l}\text { - agreement faulty: } \\
\text { subject and verb } \\
\text { - pronoun use faulty: } \\
\text { gender/agreement } \\
\text { - verbs faulty: } \\
\text { _ form } \\
\text { _ tense } \\
\text { - tense sequence } \\
\text { - passives (for } \\
\text { intransitive } \\
\text { verbs) }\end{array}$ & $\begin{array}{l}\text { - wrong part of speech } \\
\text { - wrong word I: (major } \\
\text { - obscuring meaning) } \\
\text { countable/uncountable } \\
\text { nouns misused } \\
\text { - faulty agreement of } \\
\text { parts of speech } \\
\text { illogical transitional } \\
\text { word }\end{array}$ & \\
\hline & -4 & \\
\hline $\begin{array}{l}\text { — pronoun use faulty } \\
\text { case or shift } \\
\text { - verbal use faulty } \\
\text { _ gerund } \\
\text { _ infinitive }\end{array}$ & $\begin{array}{l}\text { - articles: misused or } \\
\text { missing } \\
\text { - preposition incorrect } \\
\text { - } \text { singular/plural nouns } \\
\text { misused or confused } \\
\text { - verb idiom faulty } \\
\text { - wrong word II: (minor) } \\
\text { - word missing }\end{array}$ & \multirow{3}{*}{$\begin{array}{l}\text { misspelting } \\
\text { — punctuation }\end{array}$} \\
\hline \multirow{2}{*}{$\begin{array}{l}\text { _ pronouns vague } \\
\text { e.g. "it" "this" }\end{array}$} & -2 & \\
\hline & $\begin{array}{l}\text { — too many one-syllable/ } \\
\text { two syllable words } \\
\text { - redundancy } \\
\end{array}$ & \\
\hline
\end{tabular}




\section{EXAM MARKING SHEET}

1. Tally points off on the "Writing Assessment" form. Total these and write the total and your initials in the appropriate spaces below.

2. Convert as follows: Multiply points off by 300

Divide this by the word count

Subtract the results from 100 for final score

Student Name:

Family Name

First

Word Count:

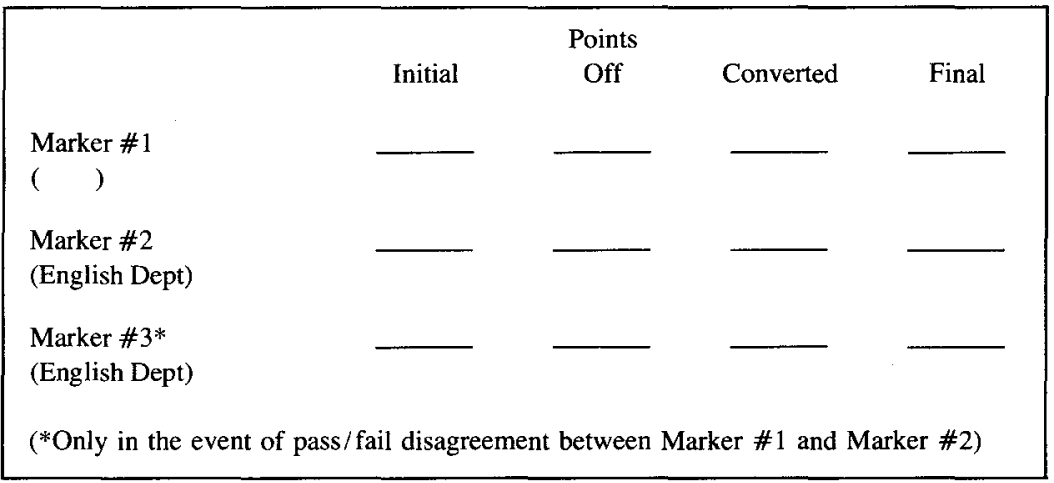

MARKER 2/3:

Final scores of less than 65 are failing scores.

FINAL ASSESSMENT: Pass _ $\quad$ Fail

If final assessment is "Fail", would you recommend/support an appeal?

Yes

No

\section{FOR OFFICE USE ONLY}

Student Name:

Family Name

First

Pass

Fail

Appeal 


\section{NOTES}

1. The use of think-aloud protocols was rejected because this might have negatively affected the subjects performing on the examination. For the same reason, a second camera was not focussed on the writers during the tasks.

2. Subjects adopted pseudonyms.

3. For $\mathrm{n}=6$ at $\mathrm{p}<.05$, a Spearman rank correlation of .829 is required for statistical significance. A Spearman rank correlation of .943 is required at $p<.01$. Had the number of subjects been nine, significant coefficients would have been .600 and .783 at $<.05$ and $<.01$ respectively. At $\mathrm{n}=12$, these would have been .497 and .591 respectively.

4. All of these six writers may have suffered from test anxiety, describing them as either High Anxious or Low Anxious was purely for comparisons within this specially selected group.

5. Removing data for Frank, whose variation in Type 2 pause ratio was in an opposite direction from the ratios of the other two High Anxious subjects, resulted in a Spearman correlation coefficient of .80 which approaches statistical significance (where the critical value for $\mathrm{p}<.05$ is .829 ).

6. In both situations, Wang wrote a rough draft which he labeled as such and wrote a final copy during his post-inscribing activities.

7. A detailed report on the profiles of these six writers which emerged from the video records and the post-hoc interviews is beyond the scope of this report. Some of the following discussion is based on these observations not reported in depth here.

\section{REFERENCES}

Adamson, H.D. (In Press). Variation theory in second language acquisition, Georgetown University Press.

Alpert, R. \& R. Haber. (1960). Anxiety in Academic Achievement Situations. Journal of Abnormal and Social Psychology, 61:2.

Anderson, C.C. (1960). The New STEP Essay Test as a Measure of Composition Ability. Educational and Psychological Measurement, XX, Spring.

Arndt, V. (1987). Six writers in search of texts: A protocol-based study of L1 and L2 writing. ELT Journal, 41:4, October.

Betancourt, F. \& M. Phinney. (1988). Sources of Writing Block in Bilingual Writers. Written Communication, 5:9, October.

Brooks, E. (1985). Case Studies of the Composing Processes of Five 'Unskilled' English-as-a-Second-Language Writers. Dissertation Abstracts International, 47:1, 164A.

Cumming, A. (1988). Writing Expertise and Second-Language Proficiency. Language Learning, 38:4.

Daly, J.A. (1978). Writing apprehension and writing competency. Journal of Educational Research, 72.

Daly, J. \& M. Miller. (1975b). The Empirical Development of an Instrument to Measure Writing Apprehension. Research in the Teaching of English, 9. 
Daly, J. \& M. Miller. (1975c). Further Studies on Writing Apprehension: SAT Scores, Success Expectations, Willingness to Take Advanced Courses and Sex Differences. Research in the Teaching of English, 9.

Daly, J.A. \& W.G. Shamo. (1978). Academic decisions as a function of writing apprehension. Research in the Teaching of English, 12.

ETS (1988). TOEFL test and score manual, Princeton, NJ: Education Testing Service.

Faigley, L., J.A. Daly \& S.P. Witte. (1981). The role of writing apprehension in writing performance and competence. Journal of Educational Research, 75.

Fayer, J. (1986). Writing Apprehension Among Puerto Rican University Students. Paper presented at the Annual Meeting of the Speech Communication Association, Chicago, November.

Fox, R. (1981). Treatment of Writing apprehension and Its Effects on Composition. Research in the Teaching of English.

Gungle, B.W. \& V. Taylor. (1989). Writing Apprehension and Second Language Writers. In D.M. Johnson, \& D.R. Roen. (Eds.) Richness in Writing: Empowering ESL Students, Longman.

Hall, C. (1987). Revision Strategies in L1 and L2 Writing Tasks: A case study. Dissertation Abstracts International, 48:5, 1187A.

Harris, M. (1985). Diagnosing Writing-Process Problems: A Pedagogical Application of Speaking-Aloud Protocol Analysis. In M. Rose. (Ed.). When a writer can't write. Guilford Press.

Heuring, D. (1985). The revision strategies of skilled and unskilled ESL writers: Five case studies. Occasional Paper \#3 of the Department of English as a Second Language of the University of Hawaii at Manoa.

Hillocks, G., Jr. (1986). Research on Written Composition: New Directions for Teaching, National Conference on Research in English.

Hunt, K.W. (1970). Syntactic Maturity in School Children and Adults, Monographs of the Society for Research in Child Development, 35, no. 1.

Jones, S. \& J. Tetroe. (1987). Composing in a Second Language. In A. Matsuhashi. (Ed.). Writing in Real Time, Ablex Publishing Corporation.

Jones, S. (1985). Problems With Monitor Use in Second Language Composition. In M. Rose. (Ed.). When a writer can't write, Guilford Press.

Jones, S. (1982). Composing in a second language: A process study. Paper presented at the annual TESOL Convention, Honolulu.

Kincaid, G. (1963). Some Factors Affecting Variations in the Quality of Students' Writing. Unpublished Ed.D. dissertation, Michigan State University, 1953. In R. Braddock, R. Lloyd-Jones, \& L. Schoer. Research in Written Composition, NCTE. 
Krashen, S. (1976). Formal and informal linguistic environments in language acquisition and language learning. TESOL Quarterly, 10.

Krashen, S. (1982). Principles and practice in second language acquisition, Oxford, Pergamon Press.

Lay, N. (1982). Composing Processes of Adult ESL Learners. TESOL Quarterly, 16:3.

Madsen, H. \& N. Murray. (1984). Retrospective Evaluation of Testing in ESL Content and Skills Courses, Brigham Young University.

Martin-Betancourt, M. (1986). The Composing Processes of Puerto Rican College Students of English as a Second Language. Dissertation Abstracts International, 47:7, 2577A.

Matsuhashi, A. \& C. Cooper. (1978). A Video Time-Monitored Observational Study: The Transcribing Behavior and Composing Processes of a Competent High School Writer. Paper presented at the annual meeting of AERA.

Perl, S. (1979). The Composing Processes of Unskilled College Writers. Research in the Teaching of English, 13:4, December.

Raimes, A. (1985). What Unskilled ESL Students Do as They Write: A Classroom Study of Composing. TESOL Quarterly, 19:1, June.

Raimes, A. (1987). Language Proficiency, Writing Ability, and Composing Strategies: A Study of ESL College Student Writers. Language Learning, 37:3, September.

Roen, D.H., V. Taylor \& K. Mangelsdorf. (1989). ESL writers at work: Process and product, Unpublished manuscript, 1987 (cited by B.V. Gungle, \& V. Taylor, Writing Apprehension and Second Language Writers, in D.M. Johnson, \& D.H. Roen. (Eds.). Richness in Writing: Empowering ESL Students, Longman.

Rose, M. .(1984). Writer's Block: The Cognitive Dimension, Southern Illinois University Press.

Rose, M. (1980). Rigid Rules, Inflexible Plans, and the Stifling of Language: A Cognitivist Analysis of Writer's Block. College Composition and Communication, 31 .

Schumacher, G., G. Klare., F. Cronin \& J. Joses. (1984). Cognitive Activites of Beginning and Advanced College Writers: A Pausal Analysis. Research in the Teaching of English, 18:2, May.

Selfe, C.L. (1985). An apprehensive writer composes. In M. Rose. (Ed.). When a writer can't write, Guilford Press.

Shaughnessy, M. (1977). Errors and expectations, A Guide for the Teacher of Basic Writing, Oxford University Press.

Speilberger, C., R. Gorsuch \& R. Lushene. (1968). Self-Evaluation Questionnaire: STAI Form X-1, Consulting Psychologists Press. 
Yau, M. (1989). A Quantitative Comparison of L1 and L2 Writing Processes. Paper presented at the annual TESOL Convention, San Antonio.

Zamel, V. (1982). Writing: The process of discovering meaning. TESOL Quarterly, 16.

Zamel, V. (1983). The Composing Processes of Advanced ESL Students: Six Case Studies. TESOL Quarterly, 17:2, June.

\section{THE AUTHOR}

Ernest Hall (M.A.) is a doctoral candidate in language education at the University of British Columbia. A former journalist with 11 years' teaching and administrative experience in ESL programmes, he has worked primarily in programmes teaching English for Academic Purposes at the English Language Institute, University of British Columbia, where he is developing procedures for teaching student writers to reflect on their composing processes. He is Past-President of the Association of British Columbia Teachers of English as an Additional Language and the B.C. representative to TESL Canada. 